\title{
Levels and Distributions of Hexachlorobutadiene and Three Chlorobenzenes in Biosolids from Wastewater Treatment Plants and in Soils within and Surrounding a Chemical Plant in China
}

Haiyan Zhang, Yawei Wang, Cheng Sun, Miao Yu, Yan Gao, Thanh Wang, Jiyan Liu,* and Guibin Jiang

State Key Laboratory of Environmental Chemistry and Ecotoxicology, Research Center for Eco-Environmental Sciences, Chinese Academy of Sciences, Beijing 100085, China

\section{Supporting Information}

\begin{abstract}
Although hexachlorobutadiene (HCBD) was recently proposed as a candidate persistent organic pollutant (POP) under the Stockholm Convention, information about its environmental levels and distributions is still very limited. In this work, HCBD was determined in the sewage sludge from 37 wastewater treatment plants (WWTPs) in 23 cities and 17 soils near a chemical plant in China. Three chlorobenzenes (CBs) (1,2,4-trichlorobenzene, 1,2,4,5-tetrachlorobenzene, and hexachlorobenzene) were simultaneously studied to help better understand the environmental behavior of HCBD. Concentrations of HCBD in sludge samples ranged from $<0.03$ to 74.3 $\mathrm{ng} / \mathrm{g}$ dry weight $(\mathrm{dw})$ with a median value of $0.30 \mathrm{ng} / \mathrm{g} \mathrm{dw}$, which was lower than those of the three CBs. Levels of HCBD

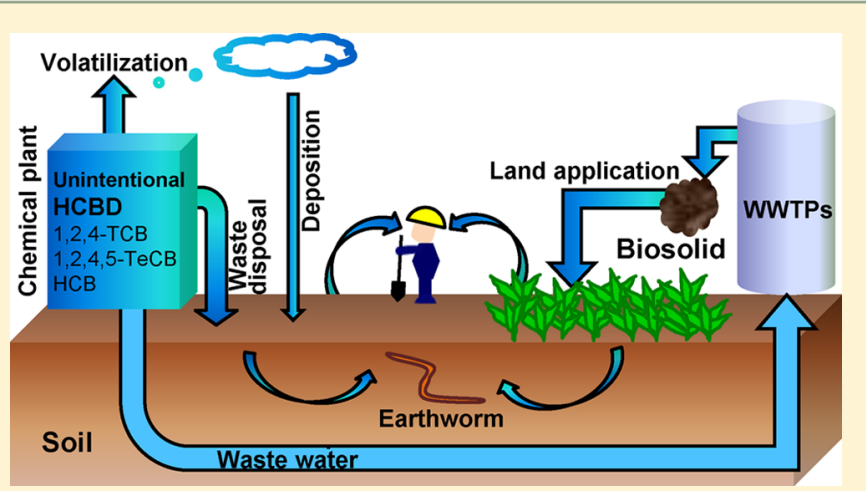
were not correlated with capacity of the WWTPs and total organic carbon. For soils, high level of HCBD was found in the sample within the plant, with a rapid decreasing concentration trend with the increase of distance from the plant. It was suspected that releasing as a byproduct during manufacturing of chlorinated chemicals was the primary source of HCBD in the studied location. Further risk assessment indicated that the environmental risk of HCBD to soil organisms and the health risk to employees were very low through soil exposure within the plant.
\end{abstract}

\section{INTRODUCTION}

Hexachlorobutadiene (HCBD), a man-made chlorohydrocarbon, has been listed as a candidate persistent organic pollutant (POP) by the Stockholm Convention in 2011 for its persistence, toxicity, bioaccumulation, and potential longrange transport abilities. ${ }^{1}$ It was used as an agricultural fumigant, intermediate in rubber, chlorofluorocarbons and lubricants, hydraulic, heat transfer or transformer liquid, laboratory reagents, as well as wash liquid for removing some hydrocarbons. ${ }^{2-4} \mathrm{HCBD}$ has been detected in various samples such as biota, ${ }^{5-8}$ food, ${ }^{9-11}$ water, ${ }^{12,13}$ leachate, ${ }^{14}$ sediment, ${ }^{15}$ air, ${ }^{16}$ and sewage sludge. ${ }^{17-19}$ To our knowledge, HCBD is not intentionally produced in large commercial quantities in China but may be unintentionally produced. Thus, investigations on the local or regional contamination and distributions of HCBD in China are urgently needed.

It had been estimated that approximately $72 \%$ of HCBD in influent was prone to accumulate on sludge from wastewater treatment plants (WWTPs). ${ }^{20}$ Therefore, concentrations of $\mathrm{HCBD}$ in sewage sludge can give an important indication on the pollution status at a local/regional basis. Meanwhile, HCBD in sewage sludge can be released to the environment through landfill, incineration and application on land, making WWTPs a possible secondary source of $\mathrm{HCBD}^{2}$ Thus, in order to investigate and control HCBD emission from WWTPs, quantification of HCBD is an important first step. Soil also plays an important role as a reservoir or sink for HCBD. ${ }^{3}$ HCBD was also found to be toxic to vine, soil microflora, and earthworms. ${ }^{21,22}$ Soil samples from different industrial plants throughout the United States were found to have detectable levels of $\mathrm{HCBD}$, and the concentrations were found to be associated with the types of production among the plants. ${ }^{23}$ However, researches on HCBD contamination from soils are still very limited, and the environmental behavior and exposure risk assessment of HCBD in soils within and surrounding point sources are not well-known.

In this study, HCBD in 37 sludge samples from WWTPs and 17 soil samples within and around a chloro-chemical plant in China were analyzed to investigate the contamination levels and geographic distributions and to estimate the effects of point source and the potential environmental risk. Hexachlorobenzene (HCB), one of the 12 initial POPs under the Stockholm Convention $^{24}$ and a benchmark substance in the multicompartment POP transport model (MSCE-POP) to evaluate longrange transport potential and persistence of $\mathrm{HCBD},{ }^{25}$ and two

Received: November 20, 2013

Revised: December 29, 2013

Accepted: January 8, 2014

Published: January 8, 2014 


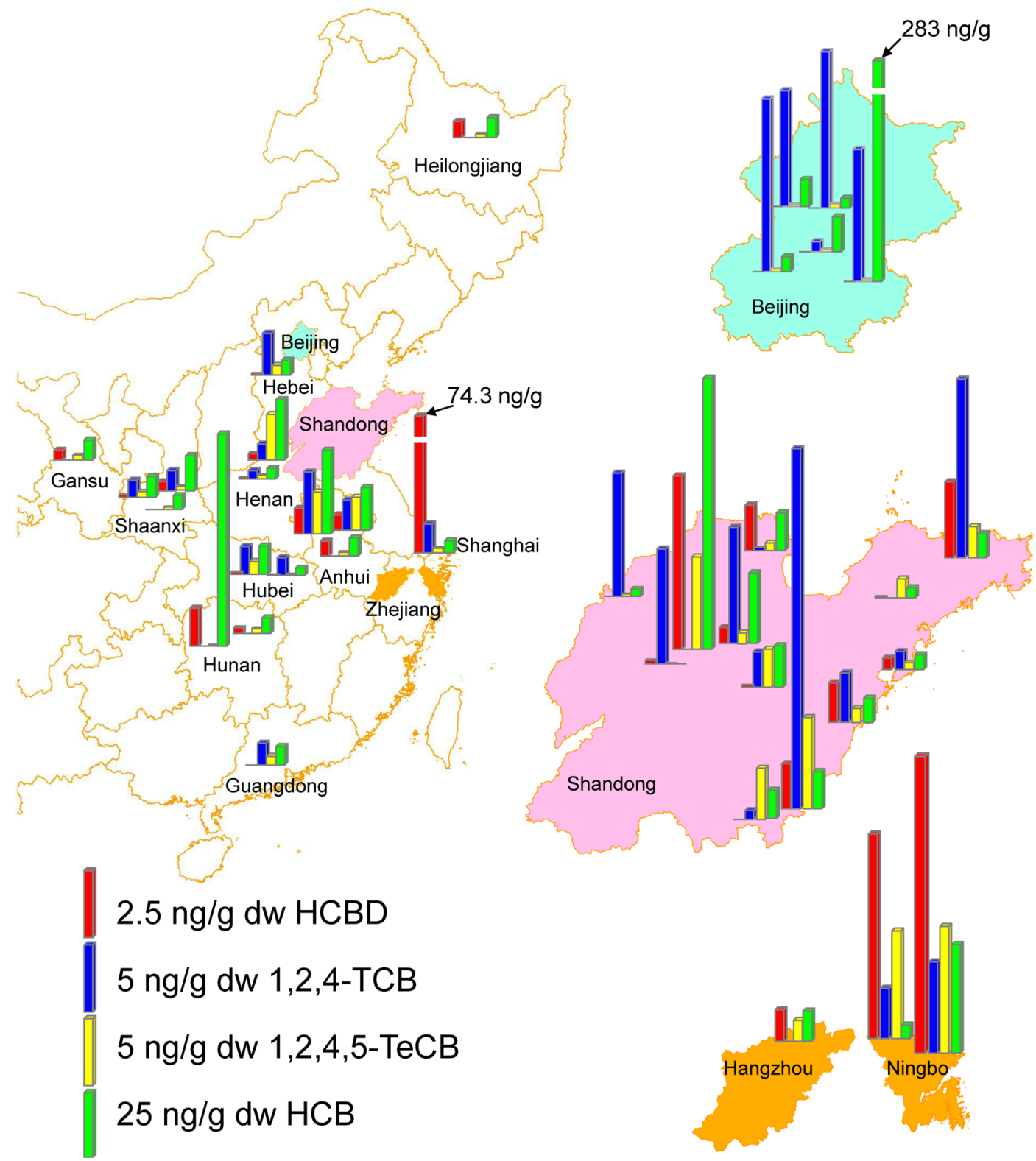

Figure 1. Levels and distributions of $\mathrm{HCBD}, 1,2,4-\mathrm{TCB}, 1,2,4,5-\mathrm{TeCB}$, and $\mathrm{HCB}$ in sewage sludge samples from Chinese WWTPs.

other chlorobenzenes (CBs) (1,2,4-trichlorobenzene (1,2,4TCB), 1,2,4,5-tetrachlorobenzene $(1,2,4,5-\mathrm{TeCB}))$ were simultaneously studied, which could be helpful to better understand the environmental behavior and fate of HCBD.

\section{EXPERIMENTAL SECTION}

Sampling Sites and Sample Collection. A total of 37 sewage sludge samples were collected from different WWTPs in China during the period of October 2010 to March 2011. The sampling sites covered 23 cities in 13 Chinese provinces (Figure 1). Basic information of the WWTPs in regard to treatment capacity, serving population, sewage sources (domestic, industrial, or combined), and type of treatment techniques as well as total organic carbon (TOC) of the samples $^{26}$ are given in the Table S1 in the Supporting Information. All sludge samples were freeze-dried and homogenized, then stored in a fridge at $-20{ }^{\circ} \mathrm{C}$ until analysis.

The selected chemical plant in the Jiangsu province is one of the largest manufacturers of chlor-alkali, chemical intermediates (such as phenyl isocyanate, hexachlorocyclopentadiene and otoluidine), flame retardant and pesticides in China. As shown in Figure 2, 17 surface soil samples within and surrounding the plant were collected at September 2011 and March 2012. Distances of the sites to the plant and TOC of the samples are listed in Table S2, Supporting Information. All soil samples were air-dried under room temperature, then store in a fridge at $-20{ }^{\circ} \mathrm{C}$ until analysis.

Chemicals. All reagents (dichloromethane, hexane, petroleum ether $\left(30-60^{\circ} \mathrm{C}\right)$ were HPLC-grade and supplied by J.T. Baker (Philipsburg, U.S.A.). Silica gel $(0.063-0.100 \mathrm{~mm})$ was obtained from Merch KGaA (Darmstadt, Germany), and Florisil (60-100 mesh) was purchased from SUPELCO Company (Sigma, U.S.A.). Analytical grade sulfuric acid, copper powder (100 mesh), and anhydrous sodium sulfate were purchased from Sinopharm Chemical Reagent (Beijing, China). Prior to use, Florisil was activated at $140{ }^{\circ} \mathrm{C}$ for $7 \mathrm{~h}$ and $5 \%$ water-deactivated; silica gel and sodium sulfate were heated 


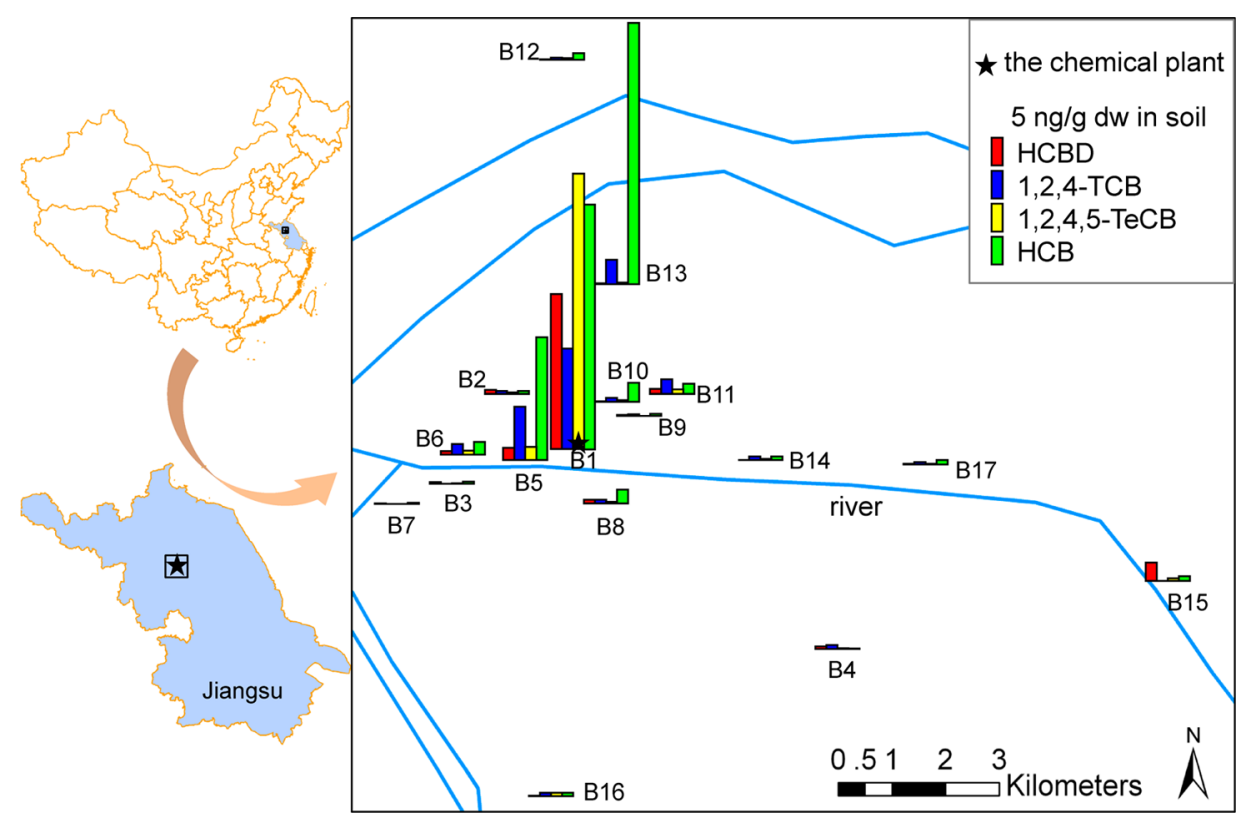

Figure 2. Levels and distributions of $\mathrm{HCBD}, 1,2,4-\mathrm{TCB}, 1,2,4,5-\mathrm{TeCB}$, and $\mathrm{HCB}$ in soils within and surrounding the chemical plant in Jiangsu province in China.

at $600{ }^{\circ} \mathrm{C}$ for $6 \mathrm{~h}$. Copper was activated with hydrochloric acid $(10 \%, \mathrm{v} / \mathrm{v})$.

The standard solution of chlorinated hydrocarbons mix (concentration: $2000 \mu \mathrm{g} / \mathrm{mL}$ each in hexane, containing 1,2,4TCB, HCB, HCBD, and 1,2,4,5-TeCB) and phenanthrene- $\mathrm{d}^{10}$ (as the injection standard for quantification) were purchased from SUPELCO company.

Sample Pretreatment. A rapid sample pretreatment procedure was developed for the analysis of HCBD, 1,2,4TCB, 1,2,4,5-TeCB, and $\mathrm{HCB}$ in sewage sludge and soil samples. Approximately $0.5 \mathrm{~g}$ dry weight $(\mathrm{dw})$ of sewage sludge or 1.0-2.0 g dw of soil sample was mixed with $10 \mathrm{~g}$ anhydrous sodium sulfate, then extracted with mixture solvent of dichloromethane/hexane $(1: 1, \mathrm{v} / \mathrm{v})$ (flush volume $60 \%)$ at $100{ }^{\circ} \mathrm{C}$ and $1500 \mathrm{psi}$ in two static extraction cycles $(10 \mathrm{~min})$ using an accelerated solvent extractor (ASE 350, Dionex, Canada). After extraction, the extract was concentrated to about $2 \mathrm{~mL}$ by rotary evaporation and then subjected to cleanup using a multilayer silica-Florisil composite column (column inner diameter $15 \mathrm{~mm}$ ). For sewage sludge, the column was filled with $6 \mathrm{~g}$ of Florisil, $1 \mathrm{~g}$ of activated silica gel, 4 $\mathrm{g}$ of acid silica gel $(30 \%, \mathrm{w} / \mathrm{w}), 1 \mathrm{~g}$ of activated silica, $5 \mathrm{~g}$ of anhydrous sodium sulfate, and $1 \mathrm{~g}$ of activated copper powder from bottom to top. For soils, the column was filled with $6 \mathrm{~g}$ of Florisil, $4 \mathrm{~g}$ of activated silica gel, $5 \mathrm{~g}$ of anhydrous sodium sulfate, and $1 \mathrm{~g}$ of activated copper powder from bottom to top. The columns were precleaned with $50 \mathrm{~mL}$ hexane and then eluted with $150 \mathrm{~mL}$ petroleum ether after sample loading. The eluate was concentrated to $50 \mu \mathrm{L}$ by rotary evaporation and gentle nitrogen gas stream. After spiking with $2 \mathrm{ng}$ of phenanthrene- $\mathrm{d}^{10}, 2 \mu \mathrm{L}$ of the final extract was injected into the instrument for quantification analysis.

Instrumental Analysis. Instrumental determination was carried out by a gas chromatograph coupled with a mass spectrometer in electron ionization mode (GC/MS QP2010, Japan) using selected ion monitoring (SIM). Chromatographic separation was achieved using a HP-5MS fused silica capillary column $(30 \mathrm{~m} \times 0.25 \mathrm{~mm}, 0.25 \mu \mathrm{m}$ film thickness, Agilent,
U.S.A.) with constant flow rate of $1.0 \mathrm{~mL} / \mathrm{min}$. The operating conditions for GC were as follows: oven temperature program was initiated at $50{ }^{\circ} \mathrm{C}$ (held for $1 \mathrm{~min}$ ), linearly increased to $100{ }^{\circ} \mathrm{C}\left(10{ }^{\circ} \mathrm{C} / \mathrm{min}\right)$, and increased to $103{ }^{\circ} \mathrm{C}$ at $1{ }^{\circ} \mathrm{C} / \mathrm{min}$, then further increased to $230{ }^{\circ} \mathrm{C}$ at $10{ }^{\circ} \mathrm{C} / \mathrm{min}$ (held for 1 min), finally ramped to $280{ }^{\circ} \mathrm{C}$ at $20^{\circ} \mathrm{C} / \mathrm{min}$ and held for 5 min. The analytes were identified by comparing the extracted ion chromatogram with those of standards. The ions of analytes selected for quantification and identification are shown in Table S3, Supporting Information, which were in conformity with those of a former study. ${ }^{15}$

\section{RESULTS AND DISCUSSION}

Quality Assurance and Quality Control (QA/QC). Strict quality assurance and control measures were executed to ensure accurate identification and quantification. Chromatograms of the analytes in standard solution, sewage sludge and soil samples are shown in Figure S1, Supporting Information. All the target compounds were baseline separated.

Procedural blanks (extraction of anhydrous sodium sulfate following the procedure described above) were performed for every batch of samples. For HCBD, no analyte was found in blanks, and a signal-to-noise ratio of 3:1 was used to calculate the method limit of detection (MDL). The three CBs in the blanks were found in the range $0.07-0.90 \mathrm{ng}$ and the reported results were all blank corrected. MDLs for the three CBs were defined as three times the standard deviations of five procedural blanks. MDLs of the four compounds were $0.01-0.22 \mathrm{ng} / \mathrm{g} \mathrm{dw}$ for sludge and soil samples. The analytes in samples were nondetectable when the results were less than the MDLs.

The method linear dynamic range (correlation coefficients $\left(R^{2}\right) \geq 0.998$ ) was $0.025-50 \mathrm{ng}$ for HCBD, 1,2,4-TCB, and $1,2,4,5-\mathrm{TeCB}$ and $0.10-150 \mathrm{ng}$ for HCB. The sludge from a WWTP in Hubei (No. A27 in Table S1, Supporting Information) and soil sample around the plant (site B16 in Figure 2) were spiked with standards to determine the method recoveries. Under optimal conditions, the spiking recoveries of the four compounds were acceptable, ranging from 51.3 to 
Table 1. Comparison of HCBD and HCB Concentrations with Other Reports (ng/g dw)

\begin{tabular}{|c|c|c|c|c|c|c|c|}
\hline \multirow[b]{2}{*}{ location } & \multirow[b]{2}{*}{$n$} & \multicolumn{2}{|l|}{ HCBD } & \multicolumn{2}{|c|}{ HCB } & \multirow[b]{2}{*}{ sample type, collected time } & \multirow[b]{2}{*}{ ref } \\
\hline & & range & mean & range & mean & & \\
\hline China & 37 & $<0.03-74.3$ & 3.12 & $<0.08-283$ & 22.5 & sludge, $2010-2011$ & this work \\
\hline China & 17 & $0.04-27.9$ & 2.22 & $0.10-47.1$ & 7.57 & soil, 2010-2011 & this work \\
\hline China & 11 & $<0.14-114$ & 38.8 & $9-3200$ & 587 & sludge, 1998-1999 & Cai et al. $(2007)^{17}$ \\
\hline China & 31 & & & $7.5-318$ & 145 & sludge, 2005 & Wang et al. $(2007)^{29}$ \\
\hline USA & & $520-8000$ & 4300 & & & sludge & Naylor et al. $(1982)^{18}$ \\
\hline USA & & $0.1-3740$ & 36 & & & sludge & Jacobs et al. $(1987)^{19}$ \\
\hline USA & 4 & $6.4 \times 10^{3}-9.8 \times 10^{5}$ & & & & $\operatorname{soil}^{a}$ & U.S. EPA $(1976)^{23}$ \\
\hline USA & 5 & $<0.1-9$ & & & & soil $^{b}$ & U.S. EPA $(1976)^{23}$ \\
\hline U.K. & 14 & & & $6.4-260$ & 42 & sludge & Stevens et al. $(2003)^{27}$ \\
\hline Korea & 6 & & & $1.3-21.5$ & 7.7 & sludge & Ju et al. $(2009)^{28}$ \\
\hline China & 5 & & & $0.90-11.79$ & 5.44 & farm soil & Song et al. $(2012)^{34}$ \\
\hline World & 191 & & & $0.01-5.20$ & 0.68 & background soil, 1998 & Meijer et al. $(2003)^{35}$ \\
\hline
\end{tabular}

${ }^{a}$ Soil samples within the plants were collected from the plants mainly producing perchoroethylene and trichloroethylene. ${ }^{b}$ Soil samples within the plants were collected from the plants mainly producing chlorine, carbon tetrachloride and triazine herbicides.

$117 \%$ for sewage sludge and from 55.0 to $119 \%$ for soil (Table S4, Supporting Information). The relative standard deviation ( $n$ $=3$ ) at the spiking levels of $0.5 \mathrm{ng}$ and $5 \mathrm{ng}$ was less than $15 \%$ for all analytes. The results indicated that the developed methods were satisfactory for analyzing four target compounds in sewage sludge and soil.

Levels and Distributions in Sewage Sludge. The levels and distributions of HCBD and three CBs in 37 sewage sludge samples are given in Figure 1. The four compounds were detected in most of the sludge samples and their median concentrations were in the following order: $\mathrm{HCB}(9.64 \mathrm{ng} / \mathrm{g}$ $\mathrm{dw})>1,2,4-\mathrm{TCB}(1.78 \mathrm{ng} / \mathrm{g} \mathrm{dw})>1,2,4,5-\mathrm{TeCB}(0.68 \mathrm{ng} / \mathrm{g}$ $\mathrm{dw})>\mathrm{HCBD}(0.30 \mathrm{ng} / \mathrm{g} \mathrm{dw})$. The results indicated that HCB was the predominant contaminant and HCBD was found at the lowest level among the targeted compounds.

The detection frequency of HCBD in sludge samples was $76 \%$, and the detectable concentrations ranged from 0.05 to $74.3 \mathrm{ng} / \mathrm{g} \mathrm{dw}$ with a median value of $0.64 \mathrm{ng} / \mathrm{g} \mathrm{dw}$, implying that contamination of HCBD is generally at very low levels in most of studied cities in China. The highest concentration of HCBD was found in the sludge from a WWTP located in Shanghai, which was followed by two samples from Ningbo city in Zhejiang province with concentrations of 7.41 and $10.7 \mathrm{ng} / \mathrm{g}$ $\mathrm{dw}$, respectively. A previous study ${ }^{17}$ detected HCBD in 11 sludge samples from Chinese WWTPs which were collected during the period from 1998 to 1999. Comparing the concentrations of HCBD in sludge samples from WWTPs located in the same areas such as Xi'an, Lanzhou and Beijing, the values in the previous study $(28-112 \mathrm{ng} / \mathrm{g} \mathrm{dw})$ were significantly higher than those $(<0.03-0.45 \mathrm{ng} / \mathrm{g} \mathrm{dw})$ in this work. This could suggest a considerable decrease of HCBD levels in the environment in the past ten years. A similar trend was also found in two early investigations from U.S.A. (Table 1). ${ }^{18,19}$ Spatial distributions of concentrations of HCBD in sewage sludge (Figure 1) showed that samples from WWTPs located in coastal areas with more developed industries such as Shandong, Shanghai, and Zhejiang had higher HCBD concentrations than those from inland areas such as Hubei, Henan, and Shaanxi. This result implied a potential link of levels of HCBD in the environment with the regional economic activities. Correlation analysis between levels of HCBD in sewage sludge and other potential influencing factors such as properties of WWTPs was performed using linear regression analysis. As shown in Table S5, Supporting Information, no obvious relationships among concentrations of HCBD and the three CBs or with the TOC of sludge were found. The relationships between levels of $\mathrm{HCBD}$ and treatment capacity, serving population of WWTPs were also not significant.

Concentrations of $1,2,4-\mathrm{TCB}$ and $1,2,4,5-\mathrm{TeCB}$ were in the range $<0.22-26.0 \mathrm{ng} / \mathrm{g} \mathrm{dw}$ and $0.07-9.25 \mathrm{ng} / \mathrm{g} \mathrm{dw}$ with detection ratios of $76 \%$ and $100 \%$, respectively. Relatively high levels of 1,2,4-TCB were found in sludge samples from Beijing and Shandong while high levels of 1,2,4,5-TeCB were found in the samples from Zhejiang, Shandong, Henan, and Anhui (Figure 1).

HCB was almost detectable in all sludge samples (37/38) which ranged from 3.58 to $283 \mathrm{ng} / \mathrm{g}$ dw with a median value of $9.70 \mathrm{ng} / \mathrm{g} \mathrm{dw}$. As shown in Table 1, the levels of HCB in the sludge samples were comparable with those in sludge samples from the U.K. ${ }^{27}$ and slightly higher than those in sludge samples from Korea. ${ }^{28}$ In the previous work by Cai et al., ${ }^{17}$ concentrations of $\mathrm{HCB}$ in the sludge samples collected in 1998-1999 were in the range 9-3200 ng/g dw with a mean value of $587 \mathrm{ng} / \mathrm{g} \mathrm{dw}$. The concentrations in sludge samples collected in 2005 decreased to the range $7.5-318 \mathrm{ng} / \mathrm{g} \mathrm{dw}$ with a mean value of $145 \mathrm{ng} / \mathrm{g} \mathrm{dw} .{ }^{29}$ Levels of HCB in the present work were significantly lower than that in those two previous works, suggesting that $\mathrm{HCB}$ contamination has continually decreased since the late 1990s. This may due to the fact that usage and production of HCB as pesticides has been banned by the Chinese government as a part of China's National Implementation Plan for Stockholm Convention since $2000 .^{30}$ However, HCB was still the predominant compound in most of sludge samples and accounted for 70 to $100 \%$ of the total of three CBs. This may be attributed to (1) HCB is still produced and used as an intermediate for PCP production in China under the exemption in Stockholm Convention. (2) $\mathrm{HCB}$ may be unintentional produced as a byproduct from several processes, such as in the production of chlorinated solvents and wood preservative. ${ }^{31}$ Different from HCBD, no obvious spatial variation was found between coastal cities and inland areas (Figure 1).

Risk Assessment of Sludge for Land Application. Humans may be exposed to the pollutants in sewage sludge through intake of plants grown on biosolids-amended soil and livestock that are kept on forage grown on biosolids-amended soil. ${ }^{32}$ According to the risk assessment process from United States Environmental Protection Agency (Part 503 biosolids 
rule), ${ }^{32}$ the limits of $\mathrm{HCBD}$ and $\mathrm{HCB}$ in biosolids causing unacceptable environmental and health effects were $6.0 \times 10^{5}$ and $2.9 \times 10^{4} \mathrm{ng} / \mathrm{g} \mathrm{dw}$ for land application. Levels of HCBD $(<0.03-74.3 \mathrm{ng} / \mathrm{g} \mathrm{dw})$ and $\mathrm{HCB}(<0.08-283 \mathrm{ng} / \mathrm{g} \mathrm{dw})$ in sludge samples in this work were much lower than those set by Part 503, indicating that the presence of HCBD and HCB in the biosolids are relatively safe for animals and human if they were applied to soils.

Levels, Distributions, and Potential Risks in Soils within and Surrounding the Plant. The concentration distributions of HCBD, 1,2,4-TCB, 1,2,4,5-TeCB, and HCB in soils within and around the chemical plant are shown in Figure 2. High concentrations of HCBD (27.9 ng/g dw), 1,2,4-TCB (18.1 ng/g dw), 1,2,4,5-TeCB (49.6 ng/g dw), and HCB (44.1 $\mathrm{ng} / \mathrm{g} \mathrm{dw}$ ) were found in the soil within the plant, which were most likely due to unintentional production as byproducts during the manufacturing of chlorinated hydrocarbons and other chlorinated chemicals. Rapid decreasing concentrations in soils were observed with the increasing distance from the plant, indicating that the manufacturing plant is the primary source of these contaminants in this location.

The highest concentration of HCBD found in the sample within the plant was slightly higher than those detected in soils $(<0.1-9 \mathrm{ng} / \mathrm{g})$ from plants producing chlorine, carbon tetrachloride, and triazine herbicides, while much lower than those in soils $\left(6.4 \times 10^{3}\right.$ to $\left.9.8 \times 10^{5} \mathrm{ng} / \mathrm{g}\right)$ from plants producing perchloroethylene and trichloroethylene (Table 1$).^{23}$ The concentrations in soil samples around the chemical plant were very low, ranging from 0.04 to $3.33 \mathrm{ng} / \mathrm{g} \mathrm{dw}$ with a median concentration of $0.23 \mathrm{ng} / \mathrm{g} \mathrm{dw}$. During production, HCBD might be formed as a byproduct and then released to the soil compartment through atmospheric deposition and disposal of waste containing HCBD. A study ${ }^{33}$ reported that only about $1 \%$ of HCBD would likely enter into the soil medium through air-soil interface. Besides, HCBD has low mobility in soils due to its high $\log K_{\mathrm{ow}}{ }^{12}$ These might be the reasons why the concentrations of $\mathrm{HCBD}$ at the sampling sites $1 \mathrm{~km}$ away from the plant were very low and about 100 times lower than that in the soil within the plant. Correlation analysis was also carried out to examine the factors that might affect the HCBD concentrations in soils. As shown in Table S6, Supporting Information, correlation coefficients among concentrations of $\mathrm{HCBD}$ and the three $\mathrm{CBs}$ in soils within and surrounding the plant varied from 0.622 to $0.993(p<0.01)$. Their significant linear relationships indicated that they may have similar environmental behavior from the point source to the surrounding areas. No obvious relationship was found between levels of HCBD and TOC in soils, whereas significant relationship was found between concentrations of HCB and TOC.

HCB could be detected in all soil samples around the plant with a mean value of $5.29 \mathrm{ng} / \mathrm{g} \mathrm{dw}$, which were comparable with that $(5.44 \mathrm{ng} / \mathrm{g} \mathrm{dw})$ in farm soils near another chemical plant producing $\mathrm{CBs}$ and pesticide in $\mathrm{China}^{34}$ while much higher than that $(0.68 \mathrm{ng} / \mathrm{g} \mathrm{dw})$ in global background surface soils. ${ }^{35}$ The distribution of HCB was somewhat different from those of other three analytes. High concentrations of HCB were not only detected in the soil within the plant but also in samples from site B5 and B13 (22.1 and $47.1 \mathrm{ng} / \mathrm{g} \mathrm{dw}$ ). Therefore, it was suspected that besides the manufacturing plant, there could also be other unknown sources responsible for the high concentrations in soils in these sites.
HCBD is toxic, persistent, and has a tendency to be accumulative in soil. ${ }^{21,22,36}$ Therefore, the ecological risk of HCBD to the sampling areas was further evaluated numerically using the Hazard Quotient (HQ) approach. HQ can be calculated as dose or EEC divided by screening benchmark, where dose is an estimated amount of contaminant taken by plant, animal or human, EEC is estimated environmental contaminant concentration at the site and screening benchmark is a no-adverse effect level. ${ }^{37}$ In general, HQ values $<1$ indicate that the likelihood of an adverse effect is very low and if the HQ value $>1$, harmful effects cannot be ruled out. The lowest half maximal lethal concentration $\left(\mathrm{LC}_{50}\right)$ could be used to calculate the predicted no effect concentration (PNEC). ${ }^{38,39}$ However, limited information on the toxicity of HCBD to soil organisms was found. We therefore use the $\mathrm{LC}_{50}$ data $(214 \mathrm{mg} / \mathrm{kg}$ for earthworm for 14 days) predicted by EPI Suite Version 4.1 for calculation. HQs of HCBD in soil samples within and around the plant were all less than 1 (Table S7, Supporting Information), indicating HCBD in these soils are considered to pose no immediate risk. The lack of the toxicity data of $\mathrm{HCBD}$ in soil increased the uncertainty in this assessment.

Human may also be exposed to the pollutants in soil. The risk of $\mathrm{HCBD}$ in the soil within the plant to employees was assessed since relatively high concentration was found there. The hazard quotient risk calculation tool ${ }^{40}$ was used to calculate $\mathrm{Hq}$ (HQ for one pathway) for accidental soil ingestion, inhalation of contaminated particles or dermal contact with contaminated soil. If the calculated $\mathrm{Hq}$ for any pathway is greater than 0.2 , health risk to human might exist. The details and results are shown in Table S8, Supporting Information. All HQs were less than 0.2 , implying very low adverse effects of HCBD in soil to workers in the plant.

\section{ASSOCIATED CONTENT}

S Supporting Information

Information of sludge and soil samples, methods, correlation analysis, and hazard quotient for ecological risk assessment. This material is available free of charge via the Internet at http://pubs.acs.org.

\section{AUTHOR INFORMATION}

\section{Corresponding Author}

*Tel.: +86 10 62849334. Fax: +8610 62849339. E-mail: liujy@ rcees.ac.cn.

Notes

The authors declare no competing financial interest.

\section{ACKNOWLEDGMENTS}

This work was jointly supported by the National Basic Research Program of China (2014CB441105) and National Natural Science Foundation of China (nos. 21337002, 21222702, 21177147).

\section{REFERENCES}

(1) POPRC-7/3: Hexachlorobutadiene; UNEP Stockholm Convention: Chatelaine, Switzerland, 2011; http://chm.pops.int/ TheConvention/POPsReviewCommittee/ReportsandDecisions/ tabid/3309/Default.aspx (accessed August 2013).

(2) Study on Waste Related Issues of Newly Listed POPs and Candidate POPs, No ENV.G.4/FRA/2007/0066; Expert Team to Support Waste Implementation (ESWI): Brussels, Belgium, 2011; http://ec.europa. eu/environment/waste/studies/pdf/POP_Waste_2011.pdf (accessed October 2013). 
(3) Lecloux, A. Hexachlorbutadiene: Sources, environmental fate, and risk characterization. Science Dossiers; Euro Chlor: Brussels, Belgium, 2004; http://www.eurochlor.org/media/14939/sd5hexachlorobutadiene-final.pdf (accessed August 2013).

(4) Denier van der Gon, H.; van het Bolscher, M.; Visschedijk, A.; Zandveld, P. Emissions of persistent organic pollutants and eight candidate POPs from UNECE-Europe in 2000, 2010, and 2020 and the emission reduction resulting from the implementation of the UNECE POP protocol. Atmos. Environ. 2007, 41 (40), 9245-9261, DOI: 10.1016/j.atmosenv.2007.06.055.

(5) Vorkamp, K.; Riget, F.; Glasius, M.; Pécseli, M.; Lebeuf, M.; Muir, D. Chlorobenzenes, chlorinated pesticides, coplanar chlorobiphenyls, and other organochlorine compounds in Greenland biota. Sci. Total Environ. 2004, 331 (1-3), 157-175, DOI: 10.1016/j.scitotenv.2004.03.027.

(6) Miège, C.; Peretti, A.; Labadie, P.; Budzinski, H.; Le Bizec, B.; Vorkamp, K.; Tronczyński, J.; Persat, H.; Coquery, M.; Babut, M. Occurrence of priority and emerging organic compounds in fishes from the Rhone River (France). Anal. Bioanal. Chem. 2012, 404 (9), 2721-2735, DOI: 10.1007/s00216-012-6187-0.

(7) Macgregor, K.; Oliver, I. W.; Harris, L.; Ridgway, I. M. Persistent organic pollutants (PCB, DDT, $\mathrm{HCH}, \mathrm{HCB}, \& \mathrm{BDE}$ ) in eels (Anguilla anguilla) in Scotland: Current levels and temporal trends. Environ. Pollut. 2010, 158 (7), 2402-2411, DOI: 10.1016/j.envpol.2010.04.005.

(8) Jürgens, M. D.; Johnson, A. C.; Jones, K. C.; Hughes, D.; Lawlor, A. J. The presence of EU priority substances mercury, hexachlorobenzene, hexachlorobutadiene, and PBDEs in wild fish from four English rivers. Sci. Total Environ. 2013, 461-462, 441-452, DOI: $10.1016 /$ j.scitotenv.2013.05.007.

(9) McConnell, G.; Ferguson, D. M.; Pearson, C. R. Chlorinated hydrocarbons and the envrionment. Endeavor 1975, 34 (121), 13-18, http://www.ncbi.nlm.nih.gov/pubmed/54249.

(10) Kotzias, D.; Klein, W.; Korte, F. Analysis of residues of hexachlorobutadiene in foodstuff and poultry. Chemosphere 1975, 4, 247-250 in German.

(11) Yurawecz, M. P.; Dreifuss, P. A.; Kamps, L. R. Determination of hexachloro-1,3-butadiene in spinach, eggs, fish, and milk by electron capture gas-liquid chromatography. J. Assoc. Off. Anal. Chem. 1976, 59 (3), 552-558, http://www.ncbi.nlm.nih.gov/pubmed/946795.

(12) Li, M. T.; Hao, L. L.; Sheng, L. X.; Xu, J. B. Identification and degradation characterization of hexachlorobutadiene degrading strain Serratia marcescens HL1. Bioresour. Technol. 2008, 99 (15), 68786884, DOI: 10.1016/j.biortech.2008.01.048.

(13) Nuhu, A. A.; Basheer, C.; Abu-Thabit, N. Y.; Alhooshani, K.; AlArfaj, A. R. Analytical method development using functionalized polysulfone membranes for the determination of chlorinated hydrocarbons in water. Talanta 2011, 87, 284-289, DOI: 10.1016/ j.talanta.2011.10.019.

(14) Matejczyk, M.; Płaza, G. A.; Nałęcz-Jawecki, G.; Ulfig, K.; Markowska-Szczupak, A. Estimation of the environmental risk posed by landfills using chemical, microbiological and ecotoxicological testing of leachates. Chemosphere 2011, 82 (7), 1017-1023, DOI: 10.1016/ j.chemosphere.2010.10.066.

(15) Lee, C. L.; Song, H. J.; Fang, M. D. Pollution topography of chlorobenzenes and hexachlorobutadiene in sediments along the Kaohsiung coast, Taiwan-A comparison of two consecutive years' survey with statistical interpretation. Chemosphere 2005, 58 (11), 1503-1516, DOI: 10.1016/j.chemosphere.2004.11.095.

(16) Juang, D. F.; Lee, C. H.; Chen, W. C.; Yuan, C. S. Do the VOCs that evaporate from a heavily polluted river threaten the health of riparian residents? Sci. Total Environ. 2010, 408 (20), 4524-4531, DOI: $10.1016 /$ j.scitotenv.2010.06.039.

(17) Cai, Q. Y.; Mo, C. H.; Wu, Q. T.; Zeng, Q. Y.; Katsoyiannis, A. Occurrence of organic contaminants in sewage sludges from eleven wastewater treatment plants, China. Chemosphere 2007, 68 (9), 17511762, DOI: 10.1016/j.chemosphere.2007.03.041.
(18) Naylor, L. M.; Loehr, R. C. Priority pollutants in municipal sewage sludge. Part I. a perspective on the potential health risks of land application[J]. Biocycle 1982, 23 (4), 18-22.

(19) Jacobs, L. W.; O’ Connor, G. A.; Overcash, M. A.; Zabik, M. J.; Rygiewicz, P. Effects of trace organics in sewage sludges on soil-plant systems and assessing their risk to humans. In Land Application of Sludge; Page, A. L., Logan, T. J., Ryan, J. A., Eds.; Lewis Publishers Inc: Chelsea, MI, 1987; pp 101-143.

(20) Schroder, H. F. Chlorinated hydrocarbons in biological sewage purification-Fate and difficulties in balancing. Water Sci. Technol. 1987, 19 (3/4), 429-438.

(21) Khokhryakovavs. Effectiveness and phytotoxicity of liquid and granulated (in tripolite) hexachlorobutadiene under moldavian conditions. Khim. Sredstva Saxhch. Rast. 1973, 3, 39-44 in Russian.

(22) Neuhauser, E. F.; Loehr, R. C.; Malecki, M. R.; Milligan, D. L.; Durkin, P. R. The toxicity of selected organic chemicals to the earthworm Eisenia fetida. J. Environ. Qual. 1985, 14, 383-388, DOI: $10.2134 /$ jeq1985.00472425001400030015x.

(23) Sampling and Analysis of Selected Toxic Substances: Task 1Bhexachlorobutadiene, EPA 560/6-76-015; Environmental Protection Agency, Office of Toxic Substaces: Washington, DC, 1976.

(24) POPRC. The 12 Initial POPs under the Stockholm Convention; UNEP, Stockholm Convention: Chatelaine, Switzerland, 2008; http:// chm.pops.int/TheConvention/ThePOPs/The12InitialPOPs/tabid/ 296/Default.aspx (accessed August 2013).

(25) Vulykh, N.; Dutchak, S.; Mantseva, E.; Shatalov, V. EMEP contribution to the preparatory work for the review of the CLRTAP protocol on persistent organic pollutants. New substances: model assessment of potential for long-range transboundary atmospheric transport and persistence of hexachlorobutadiene. Meteorological Synthesizing Centre-East: Moscow, Russia, 2005; http://www.unece. org/fileadmin/DAM/env/lrtap/TaskForce/popsxg/2005/HCBD MSCE.pdf (accessed August 2013).

(26) Ruan, T.; Liu, R.; Fu, Q.; Wang, T.; Wang, Y.; Song, S.; Wang P.; Teng, M.; Jiang, G. Concentrations and composition profiles of Benzotriazole UV stabilizers in municipal sewage sludge in China. Environ. Sci. Technol. 2012, 46, 2071-2079, DOI: 10.1021/es203376x.

(27) Stevens, J. L.; Northcott, G. L.; Stern, G. A.; Tomy, G. T.; Jones, K. C. PAHs, PCBs, PCNs, organochlorine pesticides, synthetic musks, and polychlorinated $n$-alkanes in U.K. sewage sludge: Survey results and implications. Environ. Sci. Technol. 2003, 37 (3), 462-467, DOI: $10.1021 /$ es020161y.

(28) Ju, J. H.; Lee, I. S.; Sim, W. J.; Eun, H.; Oh, J. E. Analysis and evaluation of chlorinated persistent organic compounds and PAHs in sludge in Korea. Chemosphere 2009, 74 (3), 441-447, DOI: 10.1016/ j.chemosphere.2008.09.059.

(29) Wang, Y.; Zhang, Q.; Lv, J.; Li, A.; Liu, H.; Li, G.; Jiang, G. Polybrominated diphenyl ethers and organochlorine pesticides in sewage sludge of wastewater treatment plants in China. Chemosphere 2007, 68 (9), 1683-1691, DOI: 10.1016/j.chemosphere.2007.03.060.

(30) Wang, G.; Lu, Y.; Han, J.; Luo, W.; Shi, Y.; Wang, T.; Sun, Y. Hexachlorobenzene sources, levels, and human exposure in the environment of China. Environ. Int. 2010, 36 (1), 122-130, DOI: $10.1016 /$ j.envint.2009.08.005.

(31) Wei, D.; Kameya, T.; Urano, K. Environmental management of pesticidal POPs in China: past, present and future. Environ. Int. 2007, 33 (7), 894-902, DOI: 10.1016/j.envint.2007.04.006.

(32) A Guide to the Biosolids Risk Assessments for the EPA Part 503 Rule; Environmental Protection Agency: Washington, DC, 2012; http://water.epa.gov/scitech/wastetech/biosolids/503rule_index.cfm (accessed October 2013).

(33) DMER. AEL. Pathways Analysis of Hexachlorobutadiene for the Second Priority Substances List Using Fugacity Modelling. Report Prepared for Chemicals Evaluation Division; Commercial Chemials Evaluation Branch, Envrionment Canada, by Don Mackay Environmental Research (DMER): Peterborough, Ontario, and Angus Envrionmental Limited (AEL): Don Mills, Ontario, 1996.

(34) Song, Y.; Wang, F.; Bian, Y.; Zhang, Y.; Jiang, X. Chlorobenzenes and organochlorinated pesticides in vegetable soils 
from an industrial site, China. J. Environ. Sci. 2012, 24 (3), 362-368, DOI: $10.1016 /$ S1001-0742(11)60720-1.

(35) Meijer, S. N.; Ockenden, W. A.; Sweetman, A.; Breivik, K.; Grimalt, J. O.; Jones, K. C. Global distribution and budget of PCBs and $\mathrm{HCB}$ in background surface soils: Implications for sources and environmental processes. Environ. Sci. Technol. 2003, 37 (4), 667-672, DOI: $10.1021 /$ es025809l.

(36) Fragiadakis, A.; Klein, W.; Korte, F.; Moza, P. N.; Scheunert, I.; Vockel, D.; Weiss, U. Behaviour of organohalogen compounds in the plant-soil systerms. Spez. Ber. Kemforschungsanlage Juelich 1979, 45, 144-155 in German.

(37) Ecological Risk Assessment Step 2; U.S. Environmental Protection Agency: Washington, DC, 2011; http://www.epa.gov/R5Super/ ecology/erasteps/erastep2.html (accessed October 2013).

(38) Zolezzi, M.; Cattaneo, C.; Tarazona, J. V. Probabilistic ecological risk assessment of 1,2,4-trichlorobenzene at a former industrial contaminated site. Environ. Sci. Technol. 2005, 39 (9), 29202926, DOI: 10.1021/es049214x.

(39) EuroChlor. Euro Chlor risk assessment for the marine envrionment, OSPARCOM Region-North Sea: hexachlorobutadiene; EuroChlor: Brussels, Belgium, 2002; http://www.eurochlor.org/media/49369/811-4-17_marine_ra_hcbd.pdf (accessed October 2013).

(40) Hazard quotient risk calculation tool; http://www.popstoolkit. com/tools/HHRA/NonCarcinogen.aspx (accessed October 2013). 